\title{
Metamorphosen der Haut im antiken Mythos*
}

\author{
Metamorphoses of the Skin in Greek Mythology
}

\section{Bibliografie}

DOI $10.1055 / \mathrm{s}-2007-966278$

Akt Dermatol 2007; 33:

96-97 @ Georg Thieme

Verlag KG Stuttgart · New York

ISSN 0340-2541

Korrespondenzadresse Dr. Waltrud Wamser-Krasznai Kleeberger Straße 10 35510 Butzbach

\section{Zusammenfassung \\ $\nabla$}

In der griechischen Mythologie finden sich zahlreiche Beispiele von Metamorphosen, die sich an

Die Zahl der mythischen Verwandlungen in der Griechischen Sagenwelt ist groß. Trifft man eine Auswahl unter den Metamorphosen, die sich an der Haut abspielen, wird deutlich, dass sich die bekanntesten und spektakulärsten im Umfeld der göttlichen Geschwister, Artemis und Apollon, ereignen. Beide Gottheiten sind gleichermaßen strenge Rächer beim Verstoß gegen Recht und Sitte; doch die Gründe, die zur Verwandlung ihrer jeweiligen Gefährten führen, sind durchaus unterschiedlich. Zwei Beispiele von jedem soll dies erläutern.

\section{Artemis straft Verletzungen der jungfräulichen Integrität}

1. Bevor Kallisto, die „Schönste“, sich dem Gefolge der Artemis anschließt, gelobt sie ebenfalls Keuschheit. Als die Göttin eines Tages dennoch die von Zeus verursachte Schwangerschaft der Gefährtin entdecken muss, lässt sie ihr im Zorn ein dichtes Bärenfell und Krallen wachsen. Was Kallisto dann zustößt, wird in verschiedenen Parallelmythen berichtet. Ob sie von den Pfeilen ihrer Herrin, der jungfräulichen Artemis, oder von Hera, der eifersüchtigen Gemahlin des Zeus, getötet wird - jedenfalls kreist sie seither als Sternbild der „Großen Bärin“ um den Polarstern (৫ Abb. 1).

2. Dem Jäger Aktaion, der die Göttin Artemis unbekleidet beim Baden überrascht, lässt diese ein Hirschfell wachsen und gibt ihm ein Geweih. So

\footnotetext{
* Herrn Prof. Dr. med. E. G. Jung zum 75. Geburtstag gewidmet.
}

der Haut abspielen. Die spektakulärsten sind im Umfeld von Artemis und Apollon angesiedelt. Je zwei Beispiele mögen dies erläutern.

erkennen ihn seine eigenen Hunde nicht mehr, schlagen die Zähne in sein Fleisch und reißen ihn in Stücke ( $\bullet$ Abb. 2).

\section{Mit Apollon ist das ganz anders} $\nabla$

Der Gott der Musen wird zwar wegen seiner Schönheit überall gerühmt, hat jedoch in der Liebe schier endlos Pech.

1. Am Anfang steht ein Exkurs, in dem das Gefieder eines Vogels von der Metamorphose betrof-

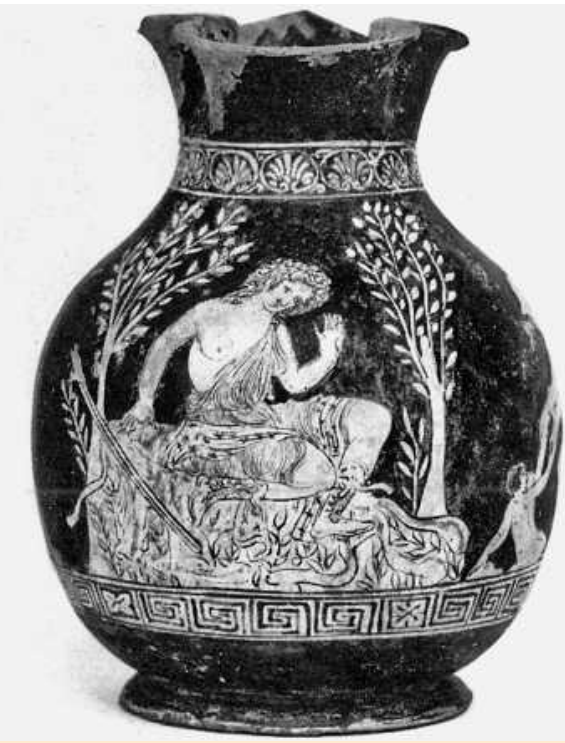

Abb. 1 Kallisto, in eine Bärin verwandelt, apulische Oinochoe (390 - 380 v. Chr.) Malibu, Inv.-Nr. 72 AE 128. Nach Schefold, 230, Abb. 320 


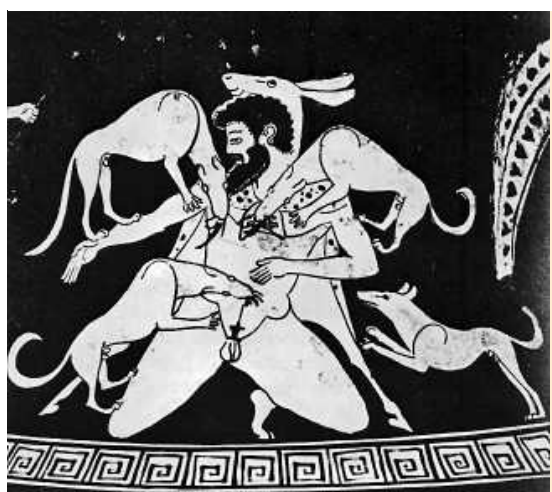

Abb. 2 Aktaion, in einen Hirsch verwandelt, Amphora des Eucharides-Malers, (nach 490 v. Chr.) Hamburg, Inv.-Nr. 1966.34. Nach Schefold, 138 Abb. 180.

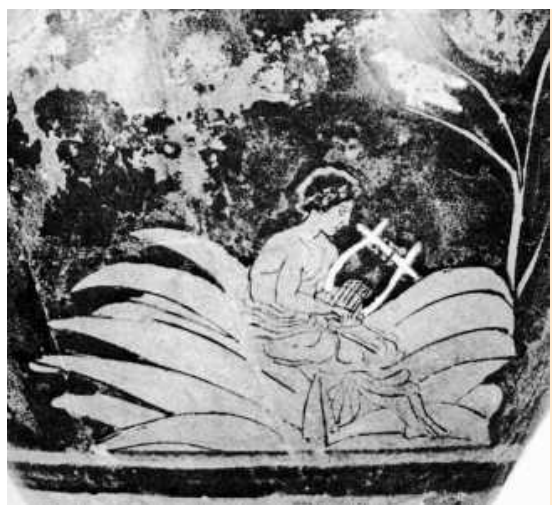

Abb. 3 Apollon und weiße Krähe, Skyphos (um 450 v. Chr.) Palermo.

Nach Schefold, 209, Abb. 284.

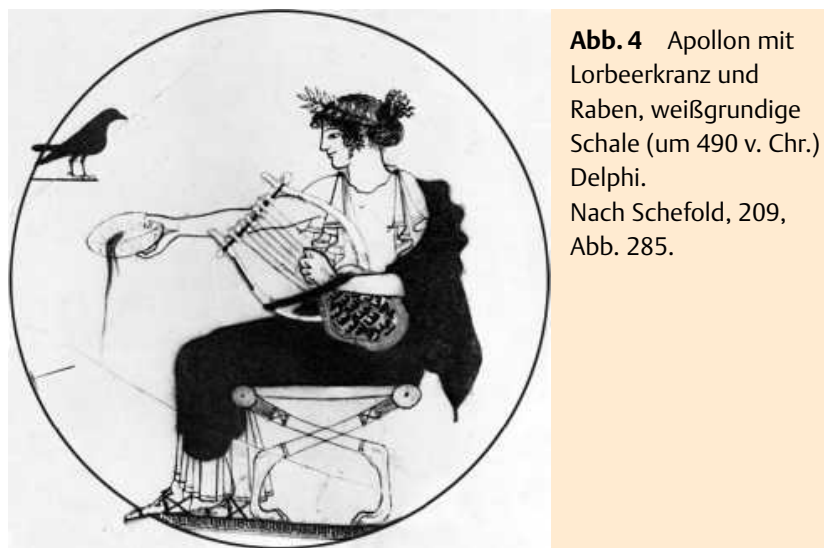

fen ist. Koronis, von Apollon schwanger, gibt sich danach auch noch einem Sterblichen hin. Flugs bringt eine weiße Krähe dem Gott die fatale Botschaft. Wie so oft trifft die Strafe den Überbringer der schlechten Nachricht; darauf wird sein weißes Gefieder rabenschwarz, was sich bekanntlich seit dieser Zeit nicht geändert hat $($ Abb. 3, $\odot$ Abb. 4)!

Der interessierte Mediziner erinnert sich an den halbwegs versöhnlichen Schluss der Geschichte: Apollon tötet die treulose Gattin, rettet aber aus ihrem Leib den noch ungeborenen Sohn, Asklepios, der dann vom weisen Chiron erzogen und in der Heilkunst unterwiesen wird.

2. Die schöne Daphne, verfolgt vom liebeskranken Apollon, flieht vor ihm „schneller als der leichte Lufthauch“ (Ovid, Metamorphosen 1,502 f.) und entzieht sich ihm am Ende ganz, indem sie sich in einen Lorbeerbaum verwandelt ( $\bullet$ Abb. 5).

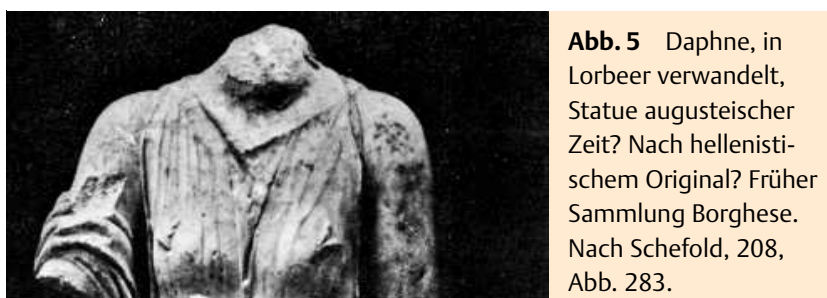

\section{Metamorphoses of the Skin in Greek Mythology} $\nabla$

In Greek mythology there are many cases of metamorphosis concerning the skin. Most of them are associated with Artemis and Apollon. This will be illustrated by two examples of each.

\section{Literatur}

1 Schefold K. Die Göttersage in der klassischen und hellenistischen Kunst. München: 1981 